Artigo Original

\title{
A inserção da prática como componente curricular em um curso de licenciatura em matemática: um estudo de caso em cálculo diferencial e integral
}

\author{
Practice as a Curricular Component in a Mathematics Undergraduate Course: A case study at \\ differential and integral calculus
}

Paulo Roberto Barbosa'

Livia Carolina Vieirall

Graziela Marchi Tiago"II

\section{Resumo}

Este trabalho tem por objetivo discutir a inserção da Prática como Componente Curricular (PCC) em um curso de Licenciatura em Matemática de um Instituto Federal de Educação, Ciência e Tecnologia, abordando alguns trabalhos desenvolvidos e planejados mais especificamente para a disciplina de Cálculo Diferencial e Integral. A legislação atualmente vigente para formação inicial em nível superior de cursos de licenciatura está estabelecida pela Resolução no. 2/2015 do CNE/CP de 01 de julho de 2015 que em seu artigo 13, dentre outros, estabelece que estes cursos deverão ter, no mínimo, 3.200 horas de efetivo trabalho acadêmico, sendo no mínimo 400 horas de PCC. Desta maneira, estudos voltados às práticas formativas que vêm sendo oferecidas mostram-se essenciais para compreensão e melhoria destas PCC aplicadas aos cursos de Licenciatura desenvolvidos nos Institutos Federais. Dentre as perspectivas alcançadas estão a possibilidade de aplicação destas atividades na educação básica e a formação de professores reflexivos, preocupados em alinhar adequadamente a prática e a teoria.

Palavras-chave: Licenciatura em matemática; Prática como componente curricular; Cálculo diferencial e integral; Educação básica

\section{Abstract}

This work aims to discuss the insertion of the Practice as a Curricular Component (PCC) in a Mathematics Undergraduate course of one Federal Institute of Education, Science and Technology, addressing some works developed and planned more specifically for the discipline of Differential and Integral Calculus. Nowadays, the legislation for initial teacher training at undergraduate courses is established by Resolution no. 2/2015 of the CNE / CP of July 1, 2015, which in article 13, among others, establishes that these courses must have at least 3,200 hours of effective academic work, these being at least 400 hours of PCC. In this way, studies focused on the training practices that are being offered are essential for understanding and improving these PCC applied to undergraduate courses developed at the Federal Institutes. Among the perspectives reached are the possibility of applying these activities in basic education and the training of reflective teachers, concerned with properly aligning practice and theory.

Keywords: Mathematics; Practice as a curricular component; Differential and integral calculus

\footnotetext{
' Professor da área de Matemática do Campus São José dos Campos, Instituto Federal de São Paulo - Brasil. E- mail: paulorb@ifsp.edu.br " Professor da área de Educação do Campus inconfidentes, Instituto Federal de São Paulo - Brasil. E- mail: livia.vieira@ifsuldeminas.edu.br I"' Professor da área de matemática do Campus São José dos Campos, Instituto Federal de São Paulo - Brasil. E- mail: graziela@ifsp.edu.br
} 


\section{Introdução}

As Resoluções do CNE/CP n. 1/2002 (BRASIL, 2002a) e CNE/CP nº. 2/2002 (BRASIL, 2002b) instituíram as Diretrizes Curriculares Nacionais para a Formação de Professores da Educação Básica, em nível superior de cursos de Licenciatura plena. Estas diretrizes orientavam que todas as disciplinas, incluindo as disciplinas pedagógicas e de formação, deveriam ser contempladas com a dimensão prática. Para esclarecimentos de como trabalhar a dimensão desta prática como componente curricular, o parecer CNE/CES n ${ }^{\circ}$. 15/2005 (BRASIL, 2005) o CNE, esclarece:

[...] a prática como componente curricular é o conjunto de atividades formativas que proporcionam experiências de aplicação de conhecimentos ou de desenvolvimento de procedimentos próprios ao exercício da docência. Por meio destas atividades, são colocados em uso, no âmbito do ensino, os conhecimentos, as competências e as habilidades adquiridas nas diversas atividades formativas que compõem o currículo do curso. As atividades caracterizadas como prática como componente curricular podem ser desenvolvidas como núcleo ou como parte de disciplinas ou de outras atividades formativas.(BRASIL,2005,p.3)

Os pareceres já indicavam a necessidade de implementação de experiências voltadas para a aplicação dos conteúdos e conhecimentos presentes nos cursos de licenciatura. Ainda que não definissem com exatidão a carga horária mínima, indicavam momentos em que poderiam ser desenvolvidas as atividades desta natureza.

A atualização das Diretrizes Curriculares Nacionais aconteceu com a Resolução nº. 2/2015 do CNE/CP (BRASIL, 2015) de 01 de julho de 2015, que em seu Art. 13 estabelece que os cursos de formação inicial de professores para a educação básica em nível superior, em cursos de licenciatura, deverão ter, no mínimo, 3.200 horas de efetivo trabalho acadêmico, em cursos com duração de, no mínimo, 8 semestres ou 4 anos, compreendendo: 400 horas dedicadas ao estágio supervisionado, na área de formação e atuação na educação básica; pelo menos 2.200 horas dedicadas às atividades formativas estruturadas conforme o projeto de curso da instituição; 200 horas de atividades teórico-práticas de aprofundamento em áreas específicas de interesse dos estudantes, por meio da iniciação científica, da iniciação à docência, da extensão e da monitoria, entre outras, consoante com o projeto de curso da instituição; também contempla o mínimo de 400 horas de PCC, distribuídas ao longo do processo formativo deste profissional e reforçando esta aplicação da prática docente não desvinculada da teoria e da prática e distribuída ao longo de todo o processo formativo deste profissional.

Considerando que este trabalho foi desenvolvido em um Instituto Federal e que por determinação da Lei 11.892/2008 (BRASIL, 2008), 20\% das vagas dos Institutos Federais devem ser destinadas a cursos de licenciatura e programas especiais de formação pedagógica com vistas à formação de professores para a educação básica, o pre- sente estudo apresentou em linhas gerais a conceituação da prática como componente curricular e analisou sua aplicação num Curso de Licenciatura em Matemática, em específico na disciplina de Cálculo Diferencial e Integral I.

A escolha da disciplina se deve a sua articulação com outras disciplinas do curso e as possibilidades de aplicação da PCC na Educação Básica. Ainda, segundo Rezende (2003), o Cálculo é uma grande rede que interage com o próprio conhecimento matemático; com a física e as ciências naturais de um modo geral; com as ciências sociais e econômicas e com o desenvolvimento de novas tecnologias. Para o autor, o Cálculo é imprescindível para a formação do cidadão.

Como procedimento metodológico, foi desenvolvida uma pesquisa qualitativa, que segundo Bogdan e Biklen (1982 apud LUDKE; ANDRÉ, 1986) envolve a obtenção de dados descritivos, obtidos no contato direto do pesquisador com a situação estudada. Pesquisas qualitativas são frequentemente utilizadas para compreender contextos e estabelecer características ou tendências. Além disto, o trabalho se caracteriza por ser um ensaio teórico ou pesquisa teórica que, segundo Fiorentini e Lorenzato (2012): “o pesquisador, neste tipo de estudo, não utiliza dados e fatos empíricos para validar uma tese ou um ponto de vista, mas a construção de uma rede de conceitos e argumentos desenvolvidos com rigor e coerência lógica”.

Como referencial teórico, foi utilizada a prática reflexiva proposta por Donald Schön (2000). O estudante, segundo Schön "tem que enxergar, por si próprio e à sua maneira, as relações entre meios e métodos empregados e resultados atingidos. Ninguém mais pode ver por ele, e ele não poderá ver apenas 'falando-se' a ele, mesmo que o falar correto possa guiar seu olhar e ajudá-lo a ver o que ele precisa ver" (DEWEY apud SCHÖN, 2000, p.25).

Schön (2000) baseia-se nos conceitos de conhecimento na ação e reflexão na ação. A reflexão se revela a partir de situações inesperadas produzidas pela ação e nem sempre o conhecimento da ação é suficiente. São três tipos distintos de reflexão: a reflexão sobre a ação, que consiste em pensar retrospectivamente sobre o que se faz; a reflexão na ação, uma reflexão no meio da ação desenvolvida, possibilitando uma interferência nesta situação; e a reflexão sobre a reflexão na ação, que consolida o entendimento sobre a reflexão na ação passada, o que possibilita a adoção desta nova estratégia.

As Diretrizes do Conselho Nacional de Educação orientam que o educador matemático deve avançar para uma visão de que a ação prática é geradora de conhecimentos e Schön (2000) defende que esses conhecimentos devem estar pautados por uma prática reflexiva. Neste contexto, estas atividades propostas de PCC especificamente na disciplina de Cálculo Diferencial e Integral, contribuem para um ensino reflexivo, no contexto da formação inicial de professores. Assim, o objetivo das atividades propostas era a busca do ensino reflexivo como proposto por Donald Schön (2000), tomando como objeto dessas reflexões os desafios e as dificuldades enfrentadas pelos alunos ao pensarem em atividades relacionando a teoria com a futura prática pedagógica. 


\section{PCC no curso de Licenciatura em Mate-} mática analisado

$\mathrm{Na}$ elaboração do projeto pedagógico do curso de Licenciatura em Matemática em questão, a PCC foi delineada de forma a possibilitar, de acordo com sua localização na estrutura curricular, diferentes possibilidades de atividades. Apenas para facilitar a apresentação deste delineamento, foi realizada uma primeira classificação das componentes em Formação específica e Formação pedagógica (Quadro 1). Esta divisão, apenas para facilitar o entendimento, representa uma classificação de acordo com a maior abordagem na componente. Por exemplo, componentes cujos objetivos sejam trabalhar conteúdos específicos de matemática foram, em geral, classificadas como sendo de formação específica. Isto não significa, no entanto, que nesta componente não serão abordados também elementos de formação pedagógica. Nossa intenção não é sugerir uma dicotomia restritiva entre os componentes, mas apenas elaborar uma classificação que facilite o entendimento.

Nas componentes chamadas de formação específica, ou seja, que abordam conteúdos de Física, Matemática, Língua Portuguesa e Libras, as atividades de PCC estão focadas no trabalho com "o ensino de". Ou seja, uma componente sobre geometria analítica, poderá, em suas atividades de PCC, discutir questões relacionadas ao ensino de geometria analítica. No primeiro ano do curso, as atividades de PCC estarão centradas em atividades voltadas ao ensino. Nas componentes classificadas como de formação pedagógica, entende-se que atividades mais amplas poderão ser desenvolvidas. Esta ampliação de horizontes foi planejada para ocorrer de forma gradual. $\mathrm{Na}$ primeira componente, prevista para o segundo ano

Quadro 1- Delineamento da PCC na estrutura curricular do curso

\begin{tabular}{|c|c|c|c|}
\hline $\begin{array}{c}\text { Classificação da } \\
\text { Componente }\end{array}$ & $\begin{array}{c}\text { Principais conteúdos } \\
\text { ou áreas }\end{array}$ & Diretrizes sugeridas & Exemplos de atividades \\
\hline $\begin{array}{l}\text { Formação } \\
\text { específica }\end{array}$ & $\begin{array}{c}\text { Matemática, Física, } \\
\text { Língua Portuguesa e } \\
\text { Libras }\end{array}$ & $\begin{array}{l}\text { Ênfase no "Ensino } \\
\text { de" (conteúdos } \\
\text { trabalhados na } \\
\text { própria componente) }\end{array}$ & $\begin{array}{l}\text { - Levantamento e análise de livros didáticos sob uma } \\
\text { perspectiva crítica. } \\
\text { - Análise da produção científica na área de ensino do } \\
\text { conteúdo específico. } \\
\text { - Elaboração e/ou análise de sequências didáticas. }\end{array}$ \\
\hline $\begin{array}{l}\text { Formação } \\
\text { pedagógica }\end{array}$ & $\begin{array}{l}\text { História da } \\
\text { Matemática e } \\
\text { Tecnologias }\end{array}$ & $\begin{array}{c}\text { Ênfase no "Ensino } \\
\text { de" (conteúdos } \\
\text { trabalhos em outras } \\
\text { componentes, } \\
\text { preferencialmente, } \\
\text { do mesmo semestre } \\
\text { letivo) e História } \\
\text { da Matemática ou } \\
\text { Tecnologias }\end{array}$ & $\begin{array}{c}\text { - Elaboração de projetos de ensino, voltados para } \\
\text { a escola básica, envolvendo o estudo do conteúdo } \\
\text { específico, aspectos históricos e uso de recursos } \\
\text { tecnológicos. } \\
\text { - Exploração de tecnologia, em particular informática, } \\
\text { conhecendo os softwares e propostas governamentais } \\
\text { para a área de Informática Educativa. } \\
\text { - Estudos interdisciplinares; Estudo, análise e vivência de } \\
\text { propostas pedagógicas na modalidade de educação não } \\
\text { presencial. }\end{array}$ \\
\hline $\begin{array}{l}\text { Formação } \\
\text { pedagógica }\end{array}$ & PCN e LBD & $\begin{array}{c}\text { Discussões em } \\
\text { contextos mais gerais. }\end{array}$ & $\begin{array}{l}\text { - Participação em movimentos de cidadania. } \\
\text { - Análise dos descritores do Sistema de Avaliação da } \\
\text { Educação Básica. } \\
\text { - Estudo e vivências das relações entre as dimensões de } \\
\text { culturas que criamos e partilhamos e a educação que } \\
\text { praticamos. } \\
\text { - Estudo de novos paradigmas educacionais. } \\
\text { - Estudo de concepções de aprendizagem e avaliação. }\end{array}$ \\
\hline $\begin{array}{l}\text { Formação } \\
\text { pedagógica }\end{array}$ & $\begin{array}{l}\text { Caracterização do } \\
\text { ambiente escolar }\end{array}$ & $\begin{array}{l}\text { Coletas e análise da } \\
\text { dados obtidos em } \\
\text { escolas de Educação } \\
\text { Básica. }\end{array}$ & $\begin{array}{c}\text { - Visitas a escolas, órgãos públicos, por exemplo, } \\
\text { Diretoria de Ensino, Fundação para o Desenvolvimento } \\
\text { da Educação e Projetos Especiais desenvolvidos por } \\
\text { Universidades ou outras Instituições. } \\
\text { - Análise das atribuições de um professor gestor. }\end{array}$ \\
\hline $\begin{array}{l}\text { Formação } \\
\text { pedagógica }\end{array}$ & Técnicas de ensino & $\begin{array}{l}\text { Enfase nas técnicas } \\
\text { e metodologias de } \\
\text { ensino. }\end{array}$ & $\begin{array}{l}\text { - Construção de material didático manipulativo. } \\
\text { - Análise de vídeo e sua utilização em sala de aula } \\
\text { e conhecer projetos desenvolvidos pela Secretaria } \\
\text { Estadual de Educação, MEC e outras Instituições. } \\
\text { - Vivências lúdicas e artísticas. } \\
\text { - Estudo da linguagem de sinais e o braille. } \\
\text { - Elaboração de propostas de ensino por meio de } \\
\text { resolução de problemas ou modelagem matemática. }\end{array}$ \\
\hline
\end{tabular}

Fonte: Elaborado pelos autores. 
do curso, é proposta uma discussão da prática pedagógica envolvendo elementos de história da matemática ou tecnologias correlacionadas aos conteúdos de outras componentes que ocorrem no mesmo semestre letivo. Esta primeira componente, portanto, rompe a barreira da sala de aula, e propõe uma primeira grande integração, por meio da PCC.

A ampliação se intensifica na componente seguinte, que aborda os PCN (Parâmetros Curriculares Nacionais) e a LDB (Lei de Diretrizes e Bases). Entende-se que neste momento as atividades de PCC poderão trabalhar temas mais gerais relacionados a educação e não mais estarem presas ao ensino de conteúdos específicos. Nos dois semestres seguintes, as disciplinas de formação pedagógica romperão a barreira da instituição formadora. Elas estarão dedicadas a caracterização do ambiente escolar, e não por acaso, aparecem no curso no momento de início dos estágios supervisionados. Estas disciplinas preveem inclusive, coletas de dados nas escolas de educação básica. Com isto, várias outras atividades de PCC podem ser desenvolvidas, conforme sugerido no Quadro 1. Na parte final do curso, as disciplinas de formação pedagógica estarão focadas em metodologias de ensino, com destaque para resolução de problemas e modelagem matemática. As atividades de PCC, portanto, na fase final do curso, estarão focadas na discussão das metodologias e em sua adequação para o trabalho com os diversos conteúdos.

\section{Atividades desenvolvidas}

Uma das atividades desenvolvidas na componente curricular de Cálculo Diferencial e Integral 1 será descrita neste artigo. Segundo o delineamento presente na estruturação do Projeto Pedagógico do Curso (PPC), a disciplina foi classificada como de formação específica na área de matemática. Portanto, a diretriz seguida foi o enfoque no ensino dos conteúdos da componente, neste caso, limites e derivadas. Optou-se neste trabalho pela discussão do tema derivadas.

Para estas atividades de PCC, os alunos foram divididos em grupos de 4 integrantes. Entende-se que o trabalho em grupo é primordial nas atividades de PCC. O trabalho em grupo, inclusive, é considerado pelos autores como uma diferenciação com relação ao estágio supervisionado. Cada grupo recebeu uma atividade elaborada pelo docente responsável. Em posse das atividades os alunos deveriam: 1) Estudar a atividade e discuti-la em grupo; 2) Elaborar em grupo a resolução da atividade e se for o caso, apontando mais de uma possibilidade de resolução; 3) Elaborar uma apresentação contendo: Descrição da atividade, Resoluções da atividade, Respostas para as seguintes perguntas:

Quais os conceitos de ensino médio estão envolvidos na atividade? Quais os conceitos de cálculo diferencial e integral estão envolvidos na atividade? Quais são, na opinião do grupo, os objetivos desta atividade? Que obstáculos seriam enfrentados na aplicação desta atividade em uma sala de aula na Educação Básica?.

Findado os trabalhos dos grupos, deu-se início a uma plenária, na qual, cada grupo realizou sua exposição e a turma toda pode discutir todas as atividades propostas. A seguir, apresenta-se uma das atividades desenvolvidas, adaptada de Pereira (2009).

O gráfico da função $s(t)=3 \sqrt{t} s(t)=3 \sqrt{t} s(t)=3 \sqrt{t}$ está representado na Figura 1 em um aplicativo para construção de gráficos. O gráfico relaciona a distância percorrida por um móvel em funcão do temno. Note que a posição do móvel no instante $t_{1}=1 t_{1}=1$ é igual a 3 , e no instante $t_{2}=5$ é aproximadamente igual a 6,7 . Vale ressaltar aqui, que o termo "aproximadamente" foi utilizado pois os valores obtidos no gráfico correspondem ao arredondamento realizado pelo programa de computador Desmos, utilizado para elaboração da questão.

\section{Figura 1: Gráfico do exemplo de atividade desenvolvida}

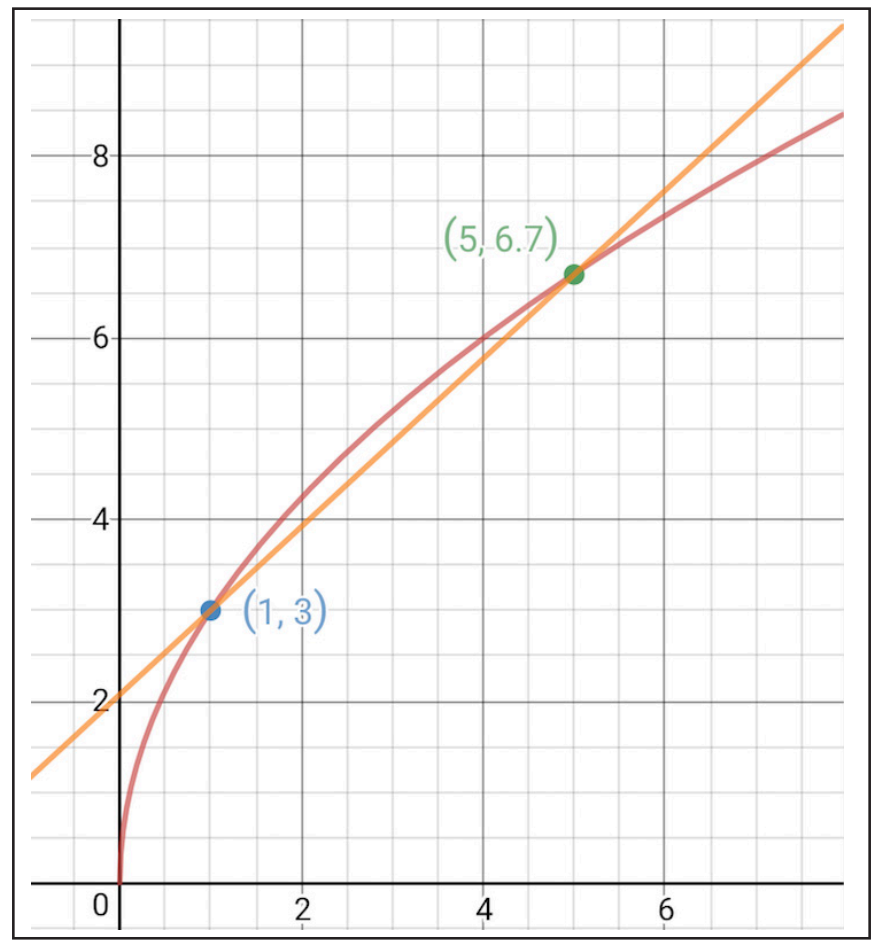

Fonte: Elaborada pelos autores

Por fim, os alunos deveriam responder questões relacionadas a posição e velocidade do móvel. Como por exemplo: Qual era a posição do móvel no instante 1 segundo? Qual era a posição do móvel no instante 5 segundos? Qual foi a velocidade média do móvel entre os instantes 1 e 5 segundos?

$\mathrm{Na}$ sequência, eles deveriam responder questões relacionadas ao gráfico apresentado, por exemplo, encontrando o coeficiente angular da reta secante também presente na Figura 1. Um exemplo de questionamento é: Qual é o coeficiente angular da reta que aparece na figura, que é secante ao gráfico de $s$, nos pontos $(1, s(1))$ e $(5, s(5))$ ?. Estas questões eram, então, repetidas para vários instantes diferentes.

O objetivo desta atividade era que os alunos associassem a taxa de variação média de uma função com o coeficiente angular da reta secante a dois pontos do gráfico da função. Esta relação foi estabelecida a medida que os alunos comparavam os resultados dos cálculos e 
observavam que, considerando os mesmos intervalos de tempo, os resultados das questões relativas a velocidade média e ao coeficiente angular eram os mesmos. Nesta atividade, portanto, foi contemplada a reflexão sobre o ensino de um conteúdo de cálculo diferencial e integral, a saber, taxa de variação média na Educação Básica. Vale ressaltar que trata-se de uma idéia fundamental para o entendimento futuro do conceito de Derivada de uma função.

\section{Conclusões e perspectivas}

A intencionalidade da atividade proposta perpassa os conceitos teóricos envolvidos nos conteúdos programáticos. Além da busca pela reflexão sobre a teoria, busca-se reflexões também sobre a ligação das teorias do ensino superior com a Educação Básica. As conclusões obtidas nas plenárias contemplam o que Schön (2000) caracteriza como reflexões sobre a ação, pois segundo relatos dos próprios alunos, colaboram no entendimento da importância da componente curricular para o trabalho do futuro professor. Alguns relatos que confirmam esta afirmação são: "Ahh agora eu entendi onde vou usar cálculo!!” , "Porque não trabalharam isto com a gente no ensino médio? Faz todo sentido!" e "Quando eu for trabalhar com funções, vou incluir este tipo de atividade!”.

Mais especificamente neste exemplo de atividade apresentado, os alunos refletiram sobre o ensino do conceito de taxa de variação na Educação Básica. Os alunos concluíram durante a plenária que a associação do conceito de taxa de variação média com o coeficiente angular da reta secante, poderia ser facilmente trabalhada na Educação Básica. Concluíram, ainda, que é possível trabalhar conceitos de cálculo diferencial e integral na Educação Básica, sem necessariamente, apresentar o formalismo habitualmente presente no material bibliográfico disponível para o ensino superior. Ponderaram, também, que o conceito de taxa de variação média, além de ser crucial para o entendimento dos conteúdos de cálculo como derivadas, melhorou a compreensão do conceito de funções. Muitos alunos relataram que pensar nos tipos de funções a partir da ideia de taxa de variação deixa muito mais clara a compreensão. Além disto, segundo os alunos, no ensino médio perde-se muito tempo com aulas sobre funções, mas com o que realmente importa, não se obtêm a ênfase merecida.

Portanto, a plenária indicou que estas reflexões sobre a ação ampliaram as possibilidades de abordagens dos conteúdos em sua futura prática docente.

A atividade de PCC realizada está de acordo com a proposta de despertar o caráter reflexivo, sem apresentar modelos prévios ou prontos de como aplicar as teorias, deixando com que os alunos orientassem as possibilidades e limites das atividades indicadas e escolhessem as abordagens adequadas. Este tipo de proposição colabora diretamente para que os alunos consigam alcançar o domínio dos saberes acadêmicos e práticos.

A formação de um professor crítico e reflexivo, que estará preparado para aplicar conhecimentos específicos em atividades da educação básica, favorece também o desenvolvimento de habilidades dos alunos dos futuros professores, quando estes estiverem no exercício da docência. Além disto, destaca-se a possibilidade mais concreta de que os alunos dos professores com este tipo de formação consigam empregar os conhecimentos adquiridos na resolução de problemas reais.

A proposta desenvolvida na disciplina de Cálculo Diferencial e Integral permitiu aos alunos percorrerem o caminho até as conclusões de forma segura e partindo da prática e análise de situações reais de aplicação dos conteúdos. Desta maneira, a PCC se constitui não só num instrumento de formação do professor reflexivo como também num espaço reflexivo, estruturado através da colaboração de todos os estudantes.

Da forma como foi possível acompanhar o desenvolvimento da PCC na disciplina, vislumbrou-se que os problemas enfrentados pelos sistemas educativos poderiam ser minimizados com o aprimoramento da formação profissional dos docentes, focada na compreensão dos processos de ensino e de aprendizagem e no domínio dos conteúdos específicos de matemática.

Este trabalho apresenta subsídios para discussão, em um cenário mais amplo, sobre como está inserida a PCC nos cursos de Licenciatura em Matemática, além de servir como ponto de partida para outros pesquisadores da temática ou docentes interessados em aprimorarem suas práticas.

Como perspectiva, acredita-se que os trabalhos desenvolvidos nas atividades de PCC, assim como o descrito neste trabalho, podem contribuir de forma significativa para a formação do futuro professor. Ou seja, espera-se que as discussões emanadas nestas atividades se reflitam na continuidade do curso, por exemplo, nas ações relacionadas ao estágio supervisionado. E neste momento, acredita-se que as outras reflexões propostas por Schön (2000), reflexão na ação e reflexão sobre a reflexão na ação poderão efetivamente ser realizadas pelo futuro professor.

\section{Referências}

BRASIL. Conselho Nacional de Educação. Resolução CNE/CP nº. 1/2002, de 18 de fevereiro de 2002a. Institui as Diretrizes Curriculares Nacionais para a Formação de Professores da Educação Básica, em nível superior, curso de licenciatura, de graduação plena. Disponível em http://portal.mec.gov.br/cne/arquivos/pdf/rcp01_02. pdf. Acesso em: 01 set. 2016.

BRASIL. Conselho Nacional de Educação. Resolução CNE/CP n․ 2/2002, de 19 de fevereiro de 2002b. Institui a duração e a carga horária dos cursos de licenciatura, de graduação plena, de formação de professores da Educação Básica em nível superior. Disponível em http://portal. mec.gov.br/cne/arquivos/pdf/CP022002.pdf. Acesso em 01 set. 2016. 
BRASIL. Conselho Nacional de Educação. Parecer CNE/ CES n. 15/2005, de 13 de maio de 2005. Solicitação de esclarecimento sobre as Resoluções CNE/CP nº. 1/2002, que institui Diretrizes Curriculares Nacionais para a Formação de Professores da Educação Básica, em nível superior, curso de licenciatura, de graduação plena, e n․ 2/2002, que institui a duração e a carga horária dos cursos de licenciatura, de graduação plena, de Formação de Professores da Educação Básica, em nível superior. Disponível em http://portal.mec.gov.br/cne/arquivos/pdf/ pces0015_05.pdf. Acesso em: 25 jun. 2017.

BRASIL. Conselho Nacional de Educação. Resolução CNE/CP nº. 2/2015, de $1^{\circ}$. de julho de 2015. Define as Diretrizes Curriculares Nacionais para a formação inicial em nível superior (cursos de licenciatura, cursos de formação pedagógica para graduados e cursos de segunda licenciatura) e para a formação continuada. Disponível em http://portal.mec.gov.br/conselho-nacionalde-educacao/atos-normativos--sumulas-pareceres-eresolucoes? $\mathrm{id}=21028$. Acesso em 08 de nov. 2015.

BRASIL. Lei no. 11.892, de 29 de dezembro de 2008. Institui a Rede Federal de Educação Profissional, Científica e Tecnológica, cria os Institutos Federais de Educação, Ciência e Tecnologia e dá outras providências. Disponível em http://www.planalto.gov.br/ccivil_03/_ ato2007-2010/2008/lei/111892.htm. Acesso em 08 nov. 2015.

FIORENTINI, D.; LORENZATO, S. Investigação em Educação Matemática - percursos teóricos e metodológicos. 2 ed. Campinas: Autores Associados, 2012.

LUDKE, M.; ANDRÉ, M. E. D. A. Pesquisa em educação: abordagens qualitativas. São Paulo: EPU, 1986.

PEREIRA, V. M. C. Cálculo no ensino médio: uma proposta para o problema de variabilidade. 2009, 182 f. Dissertação (Mestrado em Ensino de Matemática) Instituto de Matemática, Universidade Federal do Rio de Janeiro - UFRJ, Rio de Janeiro.

REZENDE, W. M. O ensino de cálculo: dificuldades de natureza epistemológica. 2003, $450 \mathrm{f}$. Tese (Doutorado em Educação) - Faculdade de Educação, Universidade de São Paulo - USP, São Paulo.

SCHÖN, D. A. Educando o Profissional Reflexivo: um novo design para o ensino e a aprendizagem. Trad. Roberto Cataldo Costa. Porto Alegre: Artmed, 2000, 256p.

\section{Contribuição dos autores:}

Paulo Roberto Barbosa

Contribuições substanciais para a concepção do trabalho; análise e interpretação de dados; redigiu o trabalho e realizou a revisão substancial

\section{Graziela Marchi Tiago}

Contribuições substanciais para a concepção do trabalho; análise e interpretação de dados; redigiu o trabalho e realizou a revisão substancial

\section{Livia Carolina Vieira}

Contribuições substanciais para a concepção do trabalho; redigiu o trabalho e realizou a revisão substancial 